\title{
Análise numérica de ligações parafusadas em chapas finas e em perfis formados a frio
}

\section{Numerical analysis of bolted connections in cold-formed steel members}

\author{
Pedro Gonçalves de Rezende'; Maximiliano Malite²; Jorge Munaiar Neto²
}

\section{Resumo}

O presente trabalho apresenta como proposta modelos numéricos tridimensionais de ligações parafusadas em chapas finas e em perfis formados a frio. Os modelos numéricos foram construídos com vistas a avaliar a resistência e o comportamento (configuração deformada) dessas ligações. Para a modelagem numérica, foi utilizado o código de cálculo ANSYS v.6.0 (programa para microcomputadores) elaborado com base no Método dos Elementos Finitos. Para avaliar a eficiência e a confiabilidade dos modelos numéricos construídos, seus resultados foram confrontados com resultados experimentais obtidos em ensaios experimentais realizados no Laboratório de Estruturas da EESC/USP. Os resultados numéricos apresentaram concordância satisfatória quando comparados com resultados experimentais.

Palavras-chave: Estruturas de aço. Perfis formados a frio. Análise numérica.

\begin{abstract}
This paper presents three-dimensional numerical models of bolted connections of cold-formed steel members. The purpose of three-dimensional numerical models is to evaluate the strength and the behavior of these connections. The computer code ANSYS v. 6.0, based on Finite Element Method, was used to analyze the numerical models response. In order to evaluate the efficiency and reliability of the constructed models, the numerical results were compared with experimental results obtained from experimental assays carried out in Structures Laboratory of EESC/USP. In this sense, the numerical results presented satisfactory agreement when compared with experimental results.
\end{abstract}

Key words: Steel Structures. Cold-formed steel members. Numerical analysis. Non-linear analysis.

\footnotetext{
${ }^{1}$ Aluno de Pós-Graduação em Estruturas da Escola de Engenharia de São Carlos da Universidade de São Paulo.(EESC/USP) ${ }^{2}$ Professor junto ao Departamento de Engenharia de Estruturas da EESC/USP
} 


\section{Introdução}

As ligações parafusadas sempre representaram (e ainda representam) um tema bastante difundido no Brasil quando se tratava de estruturas constituídas por perfis laminados e soldados, porém, pouco discutido quando se tratava de estruturas constituídas por perfis formados a frio. Este aspecto deveu-se ao fato de a antiga norma brasileira NB 143 (Cálculo de Estruturas de Aço, Constituídas por Perfis Leves) ter, na época de sua elaboração, ter omitido de suas prescrições o item "ligações". Neste caso, as ligações eram calculadas com base em normas estrangeiras. (ASSOCIAÇÃO BRASILEIRA DE NORMAS TÉCNICAS, 1967).

Com a publicação da NBR-14762 (Dimensionamento de estruturas de aço constituídas por perfis formados a frio), o tema ligações passou a ser discutido com maior frequiência. (ASSOCIAÇÃO BRASILEIRA DE NORMAS TÉCNICAS, 2001). No entanto, como ocorre com a primeira edição de qualquer documento normativo, existem algumas dúvidas com relação ao comportamento e procedimentos de cálculo destas ligações adotados pela norma brasileira. Por essa razão, acredita-se que sejam necessárias pesquisas complementares àquelas já realizadas, e mesmo àquelas em desenvolvimento, tratando do assunto ligações em perfis formados a frio.

O presente trabalho tem-se como proposta a utilização de ferramentas computacionais para a análise numérica, uma vez que análises experimentais são, em geral, realizadas com maior freqüência. Como exemplos de estudos experimentais, podem ser citados os resultados apresentados em Maiola (2004), nos quais foram largamente estudadas ligações parafusadas em chapas finas e em perfis formados a frio, com ênfase na ruptura por tração da seção líquida.

Quando se trata de modelagem numérica de estruturas metálicas e, principalmente de estruturas constituídas por perfis formados a frio, é comum realizar análises em campo bidimensional, por meio de elementos finitos do tipo casca (Shell) para representar os perfis. Trata-se de uma simplificação que, geralmente, conduz a bons resultados, alem do fato de reduzir consideravelmente o número de elementos finitos utilizados na discretização dos modelos e, consequentemente, o tempo de processamento.

No entanto, em algumas situações, como por exemplo, no caso de ligações parafusadas, a adoção de algumas condições de contorno para simular os parafusos pode comprometer os resultados das análises. Segundo Chung e Ip (2000), a primeira modelagem numérica de ligaçãoparafusada utilizando elementos finitos tridimensionais foi realizada e apresentada em Krishnamurthy e Graddy (1976). Nessa última referência, realizou-se uma análise linear elástica, simulando as condições de contato na ligação por meio da liberação ou restrição de determinados nós após cada passo de incremento de carregamento. Vale mencionar que o autor não especifica claramente como foi feita a simulação do contato.

Atualmente, com o desenvolvimento da informática e de programas que utilizam o método dos elementos finitos (MEF) cada vez mais sofisticados, já é possível simular o contato entre as partes da ligação, utilizando-se elementos de contato desenvolvidos especificamente para esta finalidade. Esses elementos de contatos, utilizados de maneira adequada, fornecem resultados bastante satisfatórios quando comparados com resultados experimentais obtidos em laboratórios.

EmChung e Ip (2000) é apresentada a modelagem de uma ligação parafusada, em campo tridimensional, a qual consiste de uma chapa fina conectada a um perfil laminado. Nessa conexão, utilizam-se elementos finitos sólidos, bem como elementos de contato que simulam o contato entre as partes da ligação. Os resultados obtidos com esta modelagem foram comparados com resultados experimentais obtidos em ensaios, e, dessa maneira, pôde-se aferir o modelo numérico proposto naquela referência.

Tendo em vista os bons resultados apresentados em Chung e Ip (2000), no presente são realizadas 
simulações numéricas em campo tridimensional para modelar ligações parafusadas em chapa finas e em perfis formados a frio. Serão utilizados elementos finitos do tipo sólido, para simular as chapas, perfis e parafusos. Para simular o contato entre as partes das ligações, serão utilizados elementos finitos do tipo contato.

O comportamento das ligações entre perfis formados a frio pode apresentardiferenças significativas quando comparado ao comportamento de ligações entre perfis laminados ou soldados. Essa diferença de comportamento se deve ao fato de as espessuras dos elementos envolvidos variarem entre $0,4 \mathrm{mme} 6,3 \mathrm{~mm}$ para os perfis formados a frio, e entre $6,3 \mathrm{~mm}$ e $50 \mathrm{~mm}$ para os perfis laminados e soldados.

A ligação parafusada deve ser capaz de transmitir a força de um elemento para o outro, por meio dos parafusos. Nas seções transversais da barra afastadas da ligação, a tensão, por simplificação, pode ser assumida com distribuição uniforme. Por outro lado, nas proximidades da região da ligação, a distribuição uniforme de tensões perde significado e passa a ser considerada como concentrada ou "estrangulada".

Como conseqüência, a seção transversal de um perfil no entorno da ligação não é solicitada na sua totalidade quando não conectada por todos os seus elementos. Isso favorece a ruptura da seção líquida e proporciona uma redução da resistência das barras submetidas à tração, e que, por sua vez, implica na diminuição da resistência dessas ligações. As normas tratam desse fenômeno por meio da aplicação de um coeficiente de redução da área bruta da seção, na região da ligação, e, dessa maneira, é obtida uma área líquida reduzida (ou efetiva).

O presente trabalho objetiva analisar numericamente o comportamento estrutural de ligações parafusadas em chapas finas e em perfis formados a frio. Para se estabelecer um tratamento numérico confiável e satisfatório dessas ligações, serão realizadas simulações numéricas em microcomputadores, utilizando o código de cálculo ANSYS v. 6.0. (1995).
Os resultados da análise numérica serão comparados com resultados experimentais apresentados em Maiola (2004), cujos ensaios foram realizados no Laboratório de Estruturas do Departamento de Engenharia de Estruturas da Escola de Engenharia de São Carlos - USP. Os modelos numéricos, desde que devidamente calibrados, constituem uma ferramenta de grande interesse em pesquisas, pois permitem obter resultados bastante satisfatórios em tempo reduzido, sem a necessidade de gastos com materiais e a mobilização de pessoal especializado.

\section{Modelos Experimentais Adotados-Aspectos de Interesse}

Nesse trabalho, foram construídos e analisados três modelos numéricos de ligações parafusadas, um modelo constituído por chapas finas e dois modelos constituídos por perfis formados a frio do tipo cantoneira de abas iguais. Os três modelos numéricos estão de acordo com os respectivos modelos experimentais, apresentados em Maiola (2004), razão pela qual foi adotada para os modelos numéricos elaborados a mesma nomenclatura dos modelos experimentais ensaiados.

O primeiro modelo experimental considerado, denominado LI1C1 para fins numéricos, consiste de uma ligação parafusada em perfil formado a frio do tipo cantoneira de abas iguais ( $L 50$ x 50 x 1,55 mm), conectada por uma das abas e composta por aço ZAR 345.

A mesma ligação apresenta três parafusos alinhados na direção da força, com furos de diâmetro $14,5 \mathrm{~mm}$, localizados no centro da aba conectada, com espaçamentos entre centros de furos e centro de furo e borda de 37,5 mm, conforme Figura 1a. $\mathrm{Na}$ análise experimental, esta configuração apresentou modo de falha por ruptura da seção líquida, com força última igual a $36,5 \mathrm{kN}$ e deslocamento total, incluindo acomodação dos parafusos no furo, igual a $10,7 \mathrm{~mm}$, conforme apresentado na Figura 1b. n, v.160, p.61-68, 1945. 

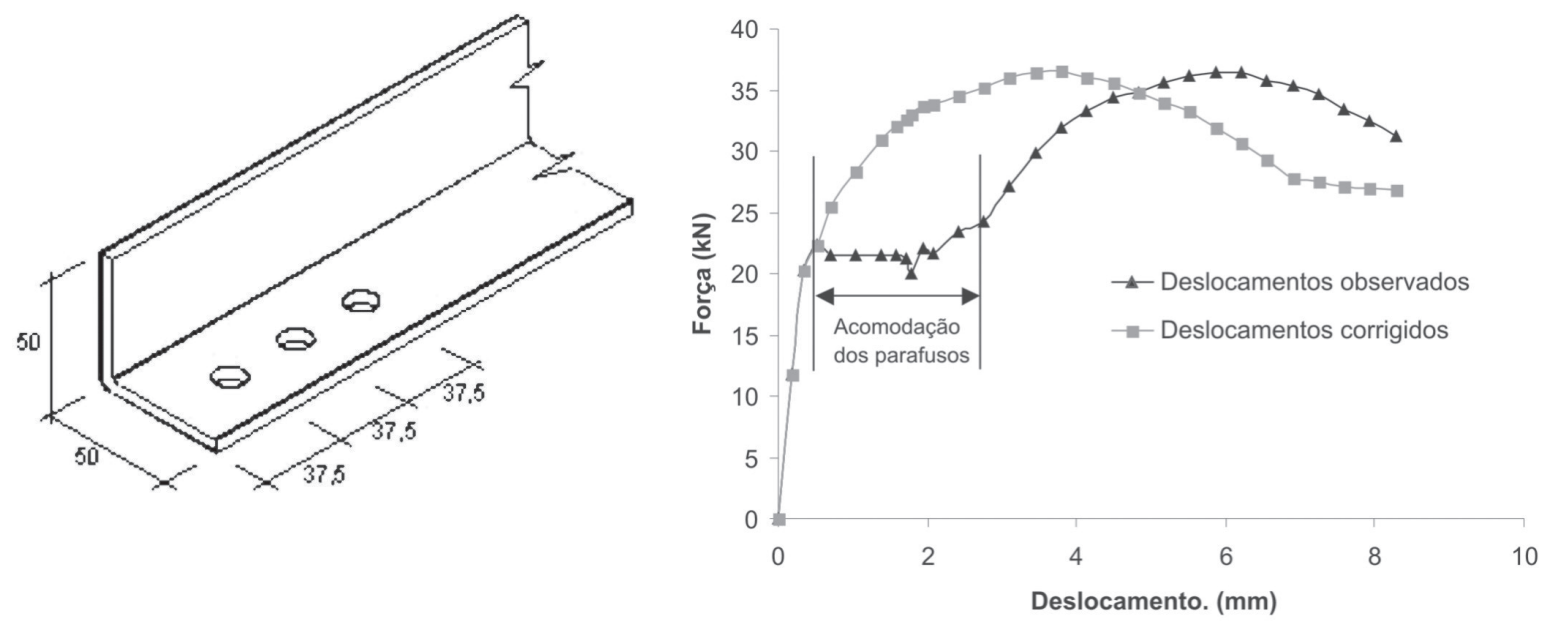

Figura 1. Modelo experimental tipo cantoneira de abas iguais com três parafusos (LI1C1): (a) Esquema do perfil ensaiado e (b) Relação Força x Deslocamento.

O segundo modelo experimental considerado, denominado LI1B1 para fins numéricos, consiste de uma ligação parafusada em perfil formado a frio do tipo cantoneira de abas iguais ( $\mathrm{L} 50 \times 50 \times 1,55 \mathrm{~mm}$ ), conectada por uma das abas e composta por aço ZAR 345. A mesma ligação apresenta dois parafusos alinhados na direção da força, com furos de diâmetro $14,5 \mathrm{~mm}$, localizados no centro da aba conectada, com espaçamentos entre centros de furos e centro de furo e borda de 37,5 mm, Figura 2a. Na análise experimental, essa configuração apresentou modo de falha por ruptura da seção líquida, com força última igual a $33,5 \mathrm{kN}$ e deslocamento total, incluindo acomodação dos parafusos no furo, igual a 10,3 $\mathrm{mm}$, conforme apresentado na Figura $2 \mathrm{~b}$.
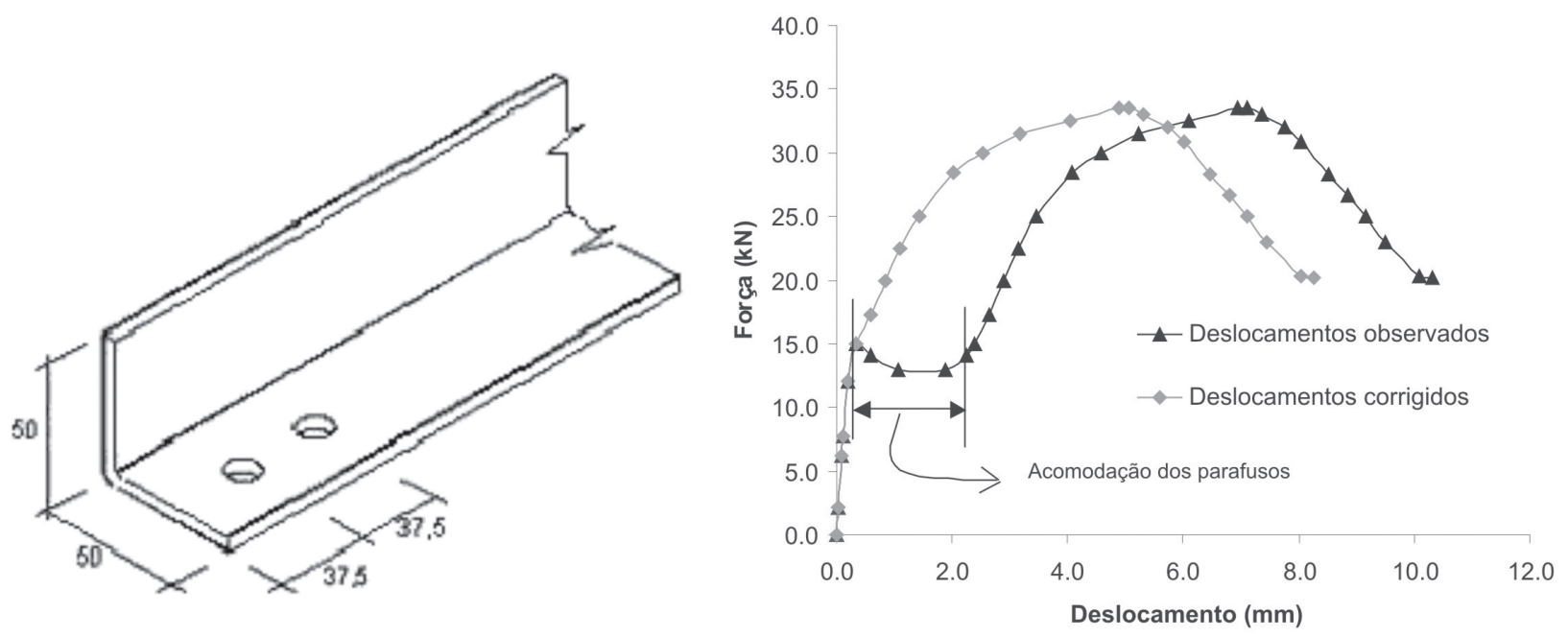

Figura 2. Modelo experimental tipo cantoneira de abas iguais com dois parafusos (LI1B1): (a) Esquema do perfil ensaiado e (b) Relação Força x Deslocamento. 
O terceiro modelo experimental considerado, denominado $\mathrm{C} 2 \mathrm{C} 1$ para fins numéricos, consiste de uma ligação parafusada em chapa fina composta por aço CSN COR $420 \mathrm{com}$ 2,0 mm de espessura. Apresenta dois furos de 14,5 mm de diâmetro na direção perpendicular à linha da força, com espaçamentos entre esses mesmos furos respeitando as distâncias mínimas estabelecidas pela NBR 14762:2001, ou seja, $3 \mathrm{~d}(37,5 \mathrm{~mm})$ entre furos e 1,5d $(18,75 \mathrm{~mm})$ entre furo e borda, estando dispostos em três seções distantes entre si $37,5 \mathrm{~mm}$, conforme Figura $3 \mathrm{a}$.

$\mathrm{Na}$ análise experimental, esta configuração apresentou modo de falha por ruptura da seção líquida, com força última igual a $48,8 \mathrm{kN}$ e deslocamento total, incluindo acomodação dos parafusos no furo, igual a $8,4 \mathrm{~mm}$, conforme diagrama apresentado na Figura $3 \mathrm{~b}$.
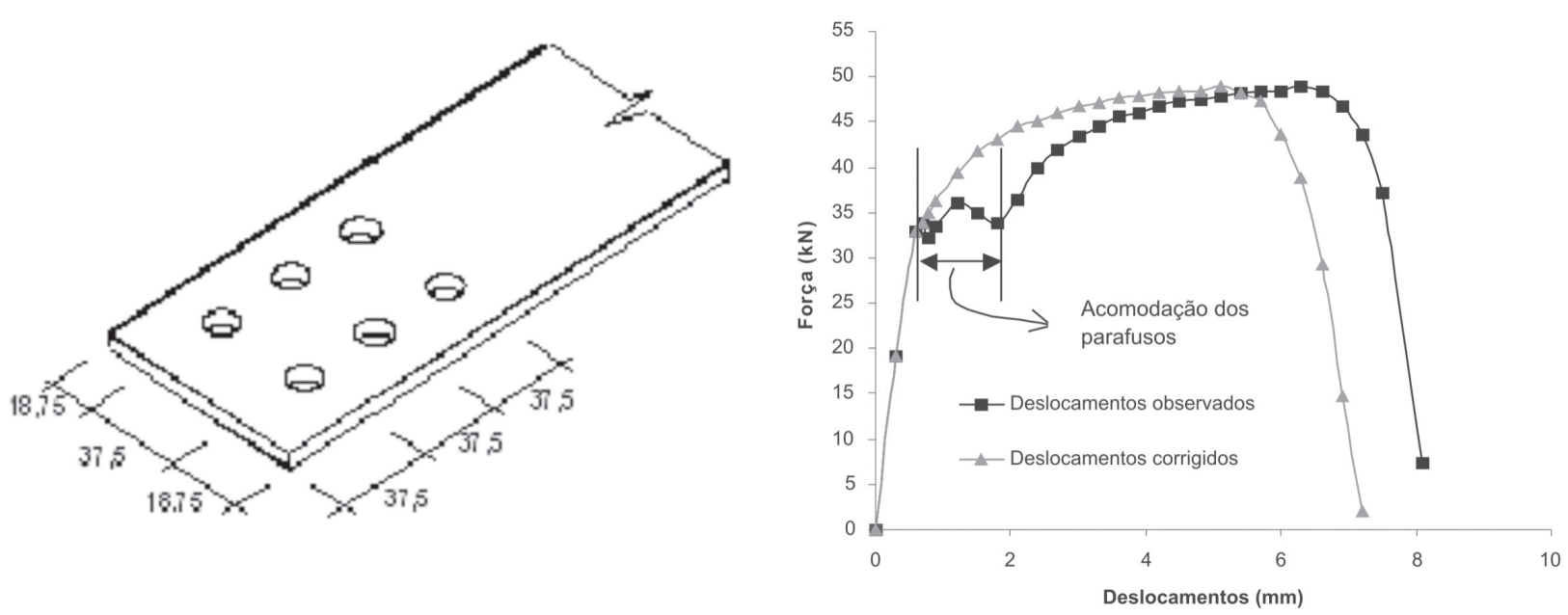

Figura 3. Modelo experimental constituído de chapa com três linhas de parafusos (C2C1): (a) Esquema do perfil ensaiado e (b) Relação Força x Deslocamento.

Durante os ensaios realizados, conforme apresentam as Figuras. 1b, 2b e 3b, uma vez vencido o atrito entre o perfil e o dispositivo de fixação, ocorreram acomodações dos parafusos nos furos padrão (gráficos construídos na cor azul).

Esse fenômeno não foi considerado nos modelos numéricos apresentados a seguir, pois, para representar esse fenômeno, seriam necessários modelos numéricos mais complexos, que englobariam aspectos que não constituem os objetivos do presente trabalho.

Nesse caso, para comparação dos resultados experimentais, o trecho de deslocamento correspondente à acomodação do parafuso foi suprimido das relações entre força e deslocamento, conforme identificado nos gráficos das Figuras.1b, $2 \mathrm{~b}$ e $3 \mathrm{~b}$ (gráficos construídos na cor vermelha).

\section{Modelos Numéricos Elaborados - Aspectos de Interesse}

A modelagem numérica de um sistema físico qualquer consiste em simular este sistema por meio de aproximações matemáticas, utilizando-se, para isso, um conjunto de elementos finitos interrelacionados que represente de maneira satisfatória o sistema de interesse analisado.

Quando se trata de modelagem numérica de estruturas metálicas e, principalmente, de estruturas constituídas por perfis formados a frio, é comum realizar análises em campo bidimensional, por meio de elementos finitos do tipo casca (Shell) para representar os perfis.

Trata-se de uma estratégia numérica que, geralmente, conduz a bons resultados, além do fato de reduzir consideravelmente o número de elementos finitos utilizados na discretização dos 
modelos e, consequentemente, o tempo de processamento. No entanto, em algumas situações, (por exemplo, nas ligações parafusadas) a adoção de algumas condições de contorno (por exemplo, simular os parafusos) pode comprometer os resultados das análises, razão pela qual serão construídos modelos numéricos tridimensionais por meio dos elementos apresentados.

\section{Elementos Finitos Utilizados}

Para a elaboração dos três modelos numéricos considerados, aqui denominados LIC1, LI1B1 e C2C1, foram utilizados alguns dos elementos finitos disponibilizados na biblioteca interna do código de cálculo ANSYS v.6. (1995). Esses modelos estão relacionados a seguir:

- Elemento finito SOLID 45 - O elemento finito denominado SOLID 45 é um elemento finito tridimensional que possui oito nós, com três graus de liberdade por nó, referentes às translações nas direções X, Y e Z (coordenadas globais).

- Elementos finitos TARGET 170 e CONTACT 174 - São elementos finitos de contato, ambos tridimensionais e utilizados em conjunto com vistas à discretizar o contato entre os componentes da ligação. Os elementos em questão possuem oito nós, apresentando três graus de liberdade por nó, referentes às translações nas direções X, Y e Z (coordenadas globais).

\section{Relação Constitutiva Adotada}

Para o presente estudo, foi adotada uma relação constitutiva considerando a não linearidade do material. Admitiu-se, para o aço, uma relação entre tensão e deformação do tipo "trilinear". Com vistas a facilitar as análises numéricas, essa mesma relação foi aplicada a todos os componentes do modelo, ou seja, para as chapas, perfis, parafusos e porcas. Essa simplificação pode ser justificada, considerando que as deformações ocorridas nos parafusos e porcas, são insignificantes quando comparadas às deformações ocorridas nas chapas e perfis cantoneira.

A Figura 4 apresenta o diagrama tensão $x$ deformação adotada nesta análise, adotado com base nos resultados de caracterização do material, apresentados em Maiola (2004). Este diagrama é representado por um trecho inicial elástico-linear, com módulo de elasticidade igual a $20.500 \mathrm{kN} / \mathrm{cm}^{2}$, para níveis de tensões variando entre zero e a tensão de proporcionalidade do aço $\left(\mathrm{f}_{\mathrm{p}}\right)$, adotada igual a $0,7 \mathrm{f}_{\mathrm{y}}$ ( $\mathrm{f}_{\mathrm{y}}$ é a resistência ao escoamento do aço).

Após o material atingir a tensão de proporcionalidade $\left(0,7 f_{y}\right)$, a relação tensão $x$ deformação deixa de ter comportamento linear e $o$ material começa a sofrer deformações plásticas. Por esta razão, foi considerado, para fins de resposta numérica, material com comportamento não-linear.

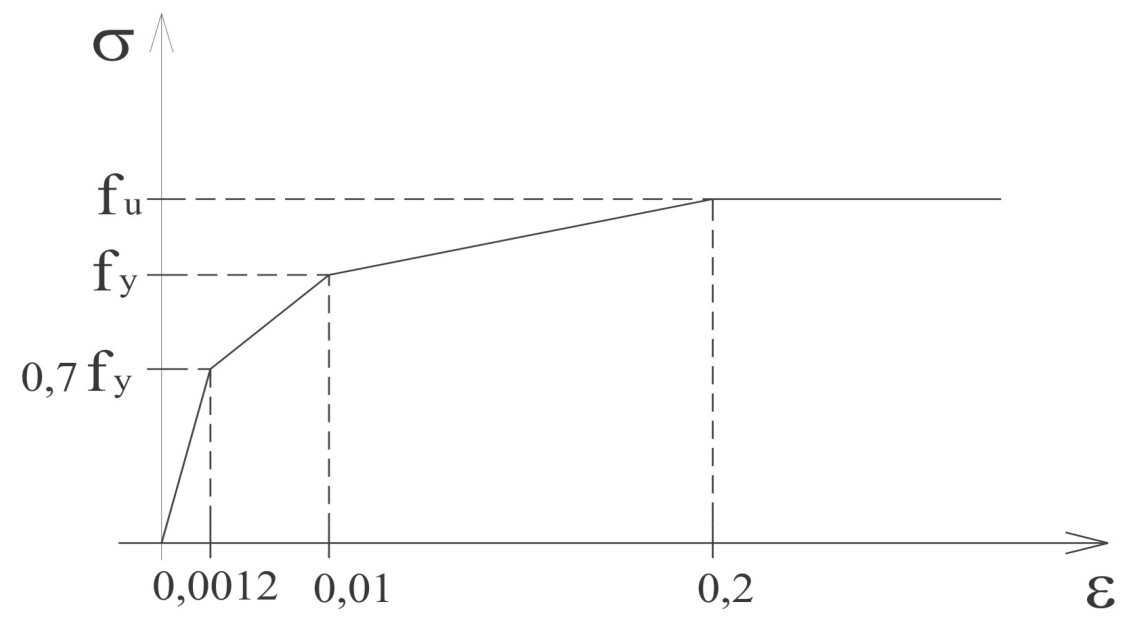

Figura 4. Diagrama tensão x deformação utilizado nos modelos numéricos analisados. 
Com o objetivo de representar a não linearidade do material, para níveis elevados de tensão, foi adotada esta relação constitutiva multilinear. $O$ valor da tensão de proporcionalidade do aço $\left(0,7 \mathrm{f}_{\mathrm{y}}\right)$, foi adotado por ser um valor bastante utilizado por pesquisadores e também sugerido em literatura especializada.

É importante salientar que a relação tensão $\mathrm{x}$ deformação aplicada ao material, pode ser uma curva composta por vários trechos. O programa ANSYS v6.0 (1995) permite a utilização de quantos trechos o usuário desejar. Nessa análise, foram utilizados apenas quatro trechos, justificados em virtude de os resultados obtidos serem satisfatórios.

Adotou-se um trecho linear para as tensões variando entre a tensão de proporcionalidade do aço $\left(0,7 f_{y}\right)$ e a tensão de escoamento do aço $\left(f_{y}\right)$, correspondendo a uma deformação e igual a 0,01 . O valor da deformação ? $=0,01$ foi adotado com o objetivo de calibrar os modelos numéricos. Em alguns trabalhos, por exemplo, em Yu (2000), esse mesmo valor é sugerido igual a 0,02 . Na última referência, não se estabelece esse valor no caso de ligações parafusadas e, nessas, circunstâncias, sugere-se que, para as ligações parafusadas, a deformação $e_{y}$ deva ser determinada experimentalmente.

Após o material atingir a tensão de escoamento $\left(\mathrm{f}_{\mathrm{y}}\right)$, admitiu-se outro segmento linear até a tensão de ruptura do material $\left(f_{u}\right)$, o que corresponde a uma deformação $?_{u}=0,2$. Para deformações acima de 0,2, admitiu-se que a tensão permanece constante e a deformação cresce indefinidamente até a ruptura do material.

\section{Condições de Contorno e de Carregamento}

As condições de contorno e de carregamento referentes aos modelos numéricos foram adotadas em concordância com aquelas consideradas nos ensaios realizados no Laboratório de Estruturas do Departamento de Engenharia de Estruturas da EESC-USP.
Os corpos-de-prova de ligações parafusadas foram ensaiados a corte simples e tiveram os deslocamentos relativos na região da ligação medidos por transdutores de deslocamentos, posicionados com base de medida inicial de 375 $\mathrm{mm}$. Em concordância com a correspondente configuração, os modelos numéricos foram construídos com $375 \mathrm{~mm}$ de comprimento, com vistas a facilitar a comparação dos resultados referentes aos deslocamentos.

Foram analisados dois tipos de ligações parafusadas em perfil do tipo cantoneira. Para ambos os modelos, LI1C1 e LI1B1, as condições de contorno e carregamento consideradas foram idênticas. Nesses modelos, o perfil foi conectado por uma de suas extremidades a uma chapa rígida por meio de três e dois parafusos respectivamente.

Nesta extremidade, foi imposta à chapa rígida restrições nas direções $\mathrm{X}, \mathrm{Y}$ e Z (coordenadas globais). Na outra extremidade do perfil, foram restringidas as translações nas direções $\mathrm{Y}$ e Z, deixando livre a translação na direção X. Nesta mesma extremidade, foram acoplados os deslocamentos na direção $\mathrm{X}$, de forma que toda a seção apresentasse os mesmos deslocamentos. Foi imposto, nessa mesma direção X, um deslocamento igual a $10 \mathrm{~mm}$, por meio de procedimento incremental-iterativo.

A Figura 5 ilustra as condições de contorno e de carregamento aplicadas para estes modelos. Nesta mesma figura, apresentam-se uma vista geral das condições de contorno e de carregamento (Figura 5a) e uma ampliação da extremidade mostrando a aplicação do carregamento e as restrições aos deslocamentos nas direções Y e Z, bem como o acoplamento dos deslocamentos na direção X (Figura 5b). Apresenta ainda uma ampliação da outra extremidade, em que se mostra as restrições aos deslocamentos nas direções X, Y e Z (coordenadas globais), imposta à chapa rígida (Figura 5c e 5d). 

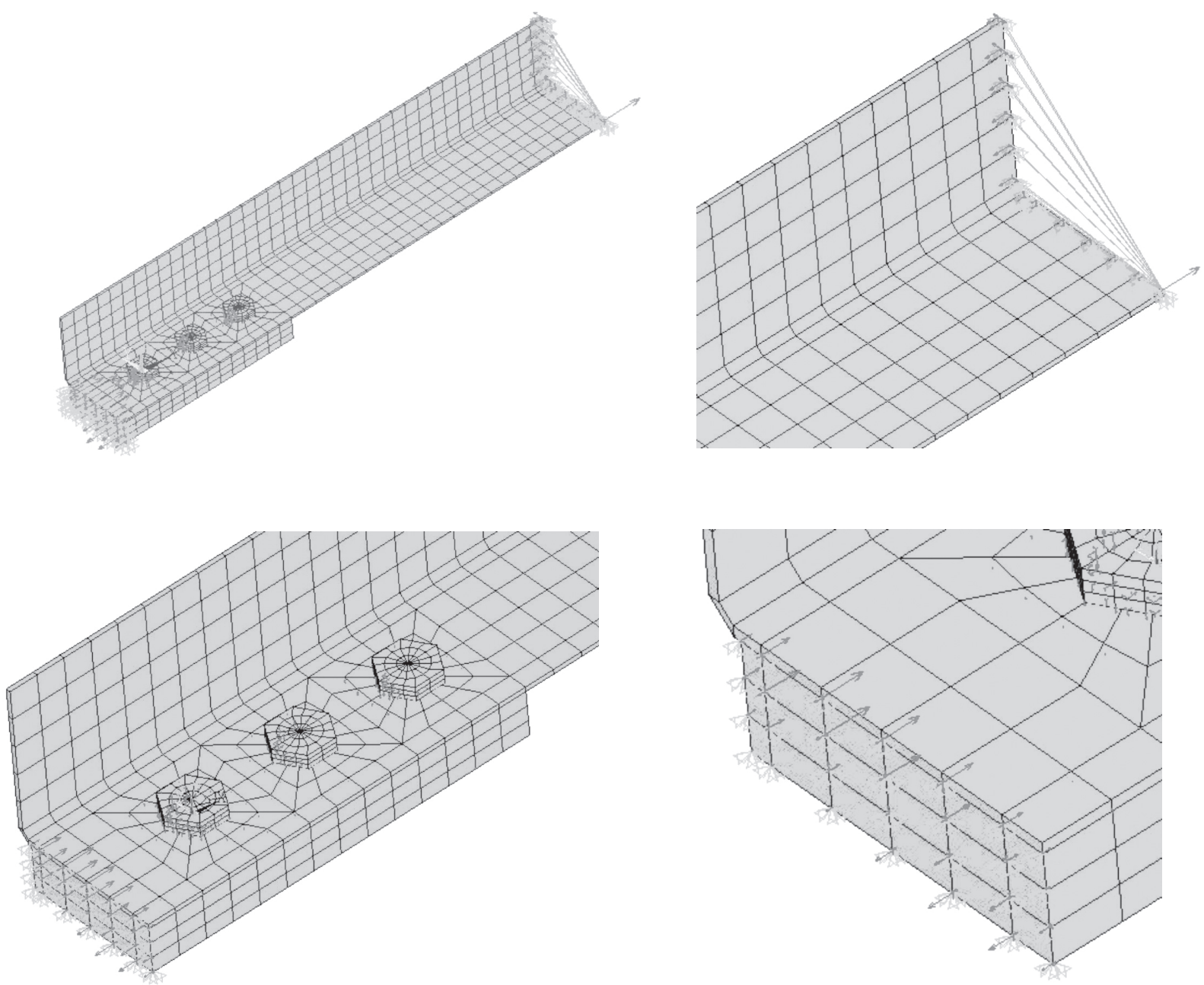

Figura 5. Condições de contorno e de carregamento adotadas para os modelos numéricos em perfil cantoneira, denominados LI1C1 e LI1B1.

Para ligação parafusada em chapa fina, foi construído e analisado o modelo numérico $\mathrm{C} 2 \mathrm{C} 1$, com condições de contorno e carregamento consideradas em concordância com o modelo experimental. A Figura 6 ilustra as condições de contorno e de carregamento aplicadas para os modelos constituídos por chapas.
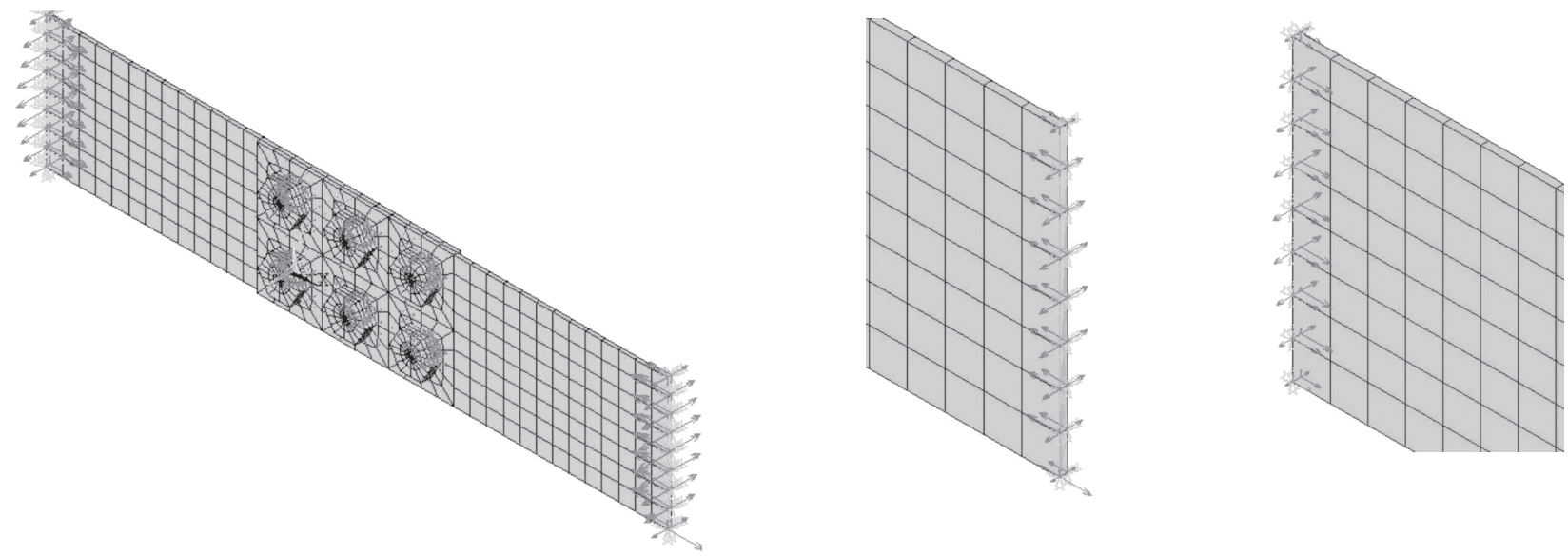

Figura 6. Condições de contorno e de carregamento para o modelos numérico em chapa C2C1. 
Na extremidade da chapa, na qual a translação na direção X é livre, foi imposto um deslocamento igual a $10 \mathrm{~mm}$, por meio de procedimento incremental-iterativo. Nessa mesma extremidade, os deslocamentos na direção $X$ foram acoplados de forma que todos os pontos da seção apresentassem os mesmos deslocamentos. Ressalta-se, ainda, que na A Figura 6 apresentam-se uma ampliação da extremidade mostrando a aplicação do carregamento e as restrições aos deslocamentos nas direções Y e Z e o acoplamento dos deslocamentos na direção X (Figura 6b), bem como uma ampliação da outra extremidade, mostrando as restrições aos deslocamentos nas direções X, Y e Z (Figura 6c).

Para simular o contato entre os vários componentes das ligações, foram utilizados elementos de contato entre o fuste do parafuso e as bordas dos furos, bem como entre a face do perfil e as faces da cabeça do parafuso. Neste modelo, uma das extremidades da chapa foi fixada restringindo-se as translações nas direções $\mathrm{X}, \mathrm{Y}$ e $\mathrm{Z}$ (coordenadas globais). Para a outra extremidade, foram restringidas apenas as translações nas direções Y eZ, deixando livre a translação em X.

\section{Análise da Resposta Numérica}

Serão apresentados neste item os resultados obtidos por meio de análises numéricas para os modelos de ligações parafusadas em chapa fina e em perfil cantoneira formados a frio. Os resultados numéricos obtidos nesta análise serão comparados

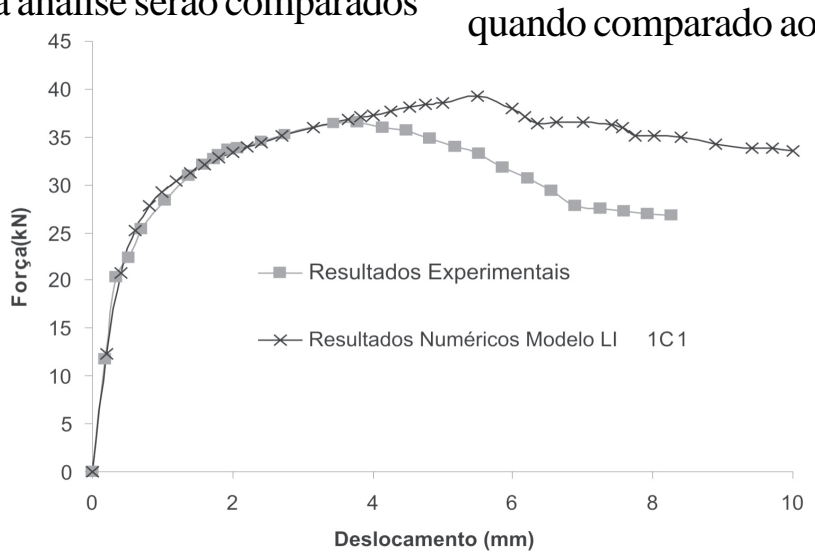

Figura (Gráfico) 7. Diagrama Força x Deslocamento: resultados experimentais e do modelo LI1C1. com resultados experimentais, uma vez que todos os tipos de ligações modelados nesta análise foram ensaiados em laboratório. Em todos os modelos numéricos analisados, os carregamentos foram aplicados indiretamente na forma de incrementos de deslocamentos.

Foram aplicados 4 (quatro) passos de carregamentos, e cada passo foi subdividido em outros 5 (cinco) ou mais sub-passos na solução do modelo. Estes sub-passos foram estabelecidos automaticamente pelo programa ANSYS v. 6.0 (1995), de maneira tal que a convergência dos resultados fosse garantida. Utilizou-se como parâmetro de convergência uma tolerância igual a 0,01 .

Em razão da forma adotada para a aplicação dos carregamentos, o procedimento utilizado para a solução do sistema de equações de equilíbrio foi do tipo "incremental-iterativo", em correspondência com o Método Full-NewtonRaphson para a solução de problemas não-lineares.

\section{Ligação parafusada em perfil cantoneira com três seções de parafusos}

A Figura 7 apresenta a curva força $x$ deslocamento para o modelo LI1C1. Nesta figura, pode-se observar que a curva obtida na análise numérica apresenta comportamento semelhante àquela obtida na analise experimental. Nesse caso, o modelo numérico apresentou resultado satisfatório quando comparado ao resultado experimental. 
No trecho inicial da curva, para valores de deslocamentos menores que $2 \mathrm{~mm}$, o modelo numérico LIIC1, apresentou rigidez ao deslocamento praticamente igual à rigidez ao deslocamento observada no ensaio experimental. No trecho intermediário da curva, para deslocamentos entre $2 \mathrm{~mm}$ e $4 \mathrm{~mm}$, observou-se uma concordância satisfatória entre o resultado numérico do modelo LI1C1 e o resultado experimental.É importante salientar que no trecho final da curva, correspondente a valores de deslocamentos maiores que $4 \mathrm{~mm}$, a comparação entre resultados numéricos e experimentais deixa de ter sentido físico, uma vez que no ensaio experimental ocorreu a ruptura da ligação, resultando em força nula.

No modelo numérico, a ruptura não pode ser identificada, tendo em vista que o material, mesmo atingindo elevadas tensões que o levam a plastificação, continua respondendo com deslocamentos sempre crescentes para força constante e, consequentemente, diferentes de zero. Comparando a força última obtida para o modelo numérico LI1C1, nota-se que essa resultou com valor igual a $39,20 \mathrm{kN}$, enquanto que no ensaio esta mesma força resultou com valor igual a $36,58 \mathrm{kN}$, cuja diferença é da ordem de 7,16\%.

A Figura 8 apresenta as curvas de isotensões para o modelo numérico LI1C1 tomadas com referência às tensões equivalentes de von Mises. Nesta figura, pode-se observar que entre o furo e a borda da cantoneira, na seção em que está localizado o primeiro parafuso, aparecem tensões da ordem das tensões de plastificação do aço. Por esta razão, a região em questão pode ser indicada como forte candidata para a ocorrência da ruptura do material, como de fato foi possível verificar no ensaio experimental.

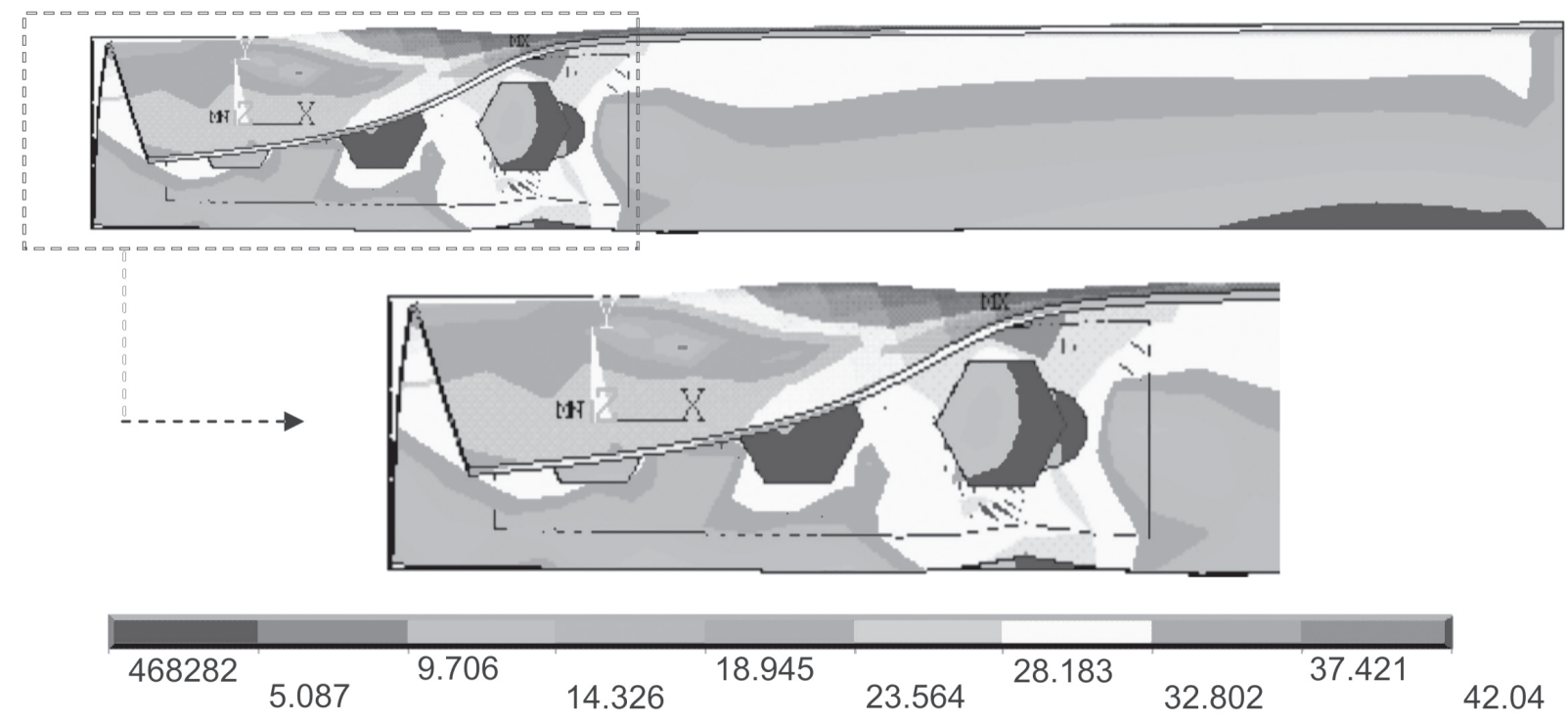

Figura 8. Tensões equivalente de von Mises para o modelo LI1C1. Unidade: kN/cm2.

A configuração deformada verificada no ensaio experimental foi satisfatoriamente recuperada no modelo numérico LI1C1, conforme representado na Figura 9, em que é mostrada em detalhe a ruptura e a configuração deformada da ligação no ensaio experimental, Figura 9a. Na mesma figura, é mostrada ainda uma ampliação da região dos parafusos do modelo numérico LI1C1, Figura 9b, em que se pode observar a deformação ocorrida na aba não conectada da cantoneira, a qual resulta em concordância com aquela identificada no ensaio. 


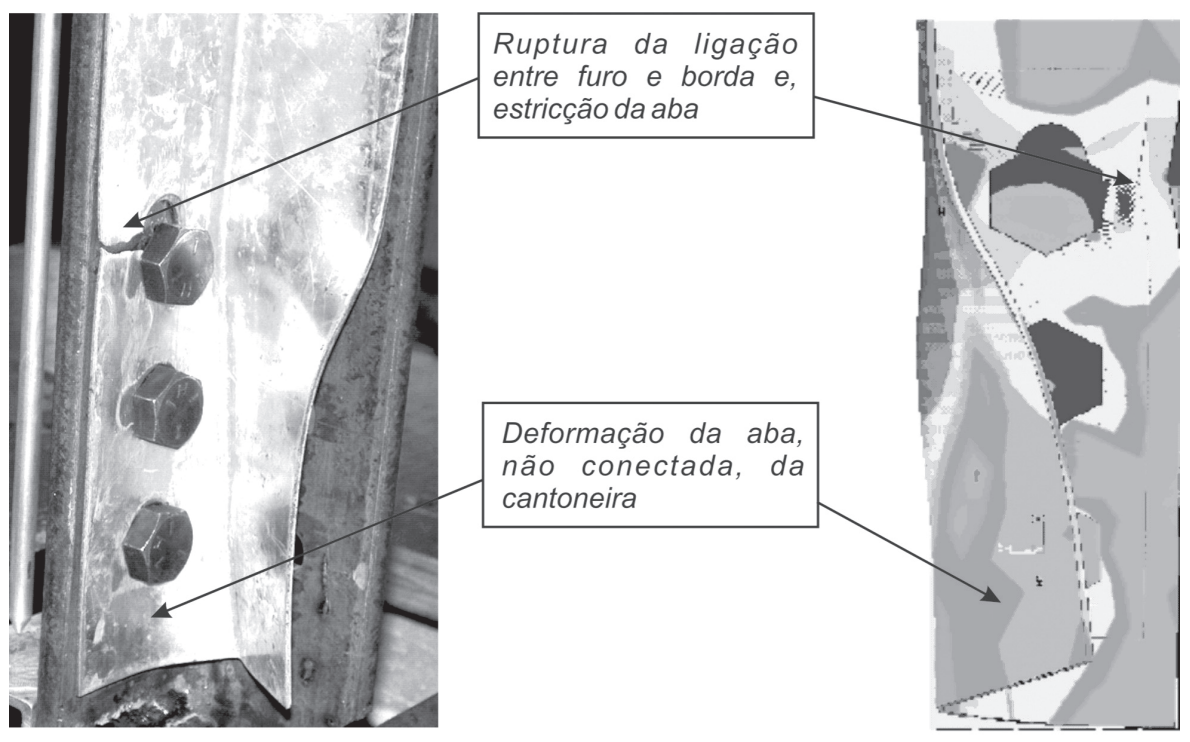

Figura 9. Ligação parafusada tipo cantoneira de abas iguais com três parafusos: (a) Modelo experimental e (b) Modelo numérico LI1C1.

\section{Ligação parafusada em perfil cantoneira com duas seções de parafusos}

A Figura 10 apresenta a curva força x deslocamento para o modelo LI1B1. Nesta figura, pode-se observar que a curva obtida na análise numérica apresenta comportamento semelhante àquela obtida na analise experimental e, portanto, satisfatório quando comparado ao resultado experimental.

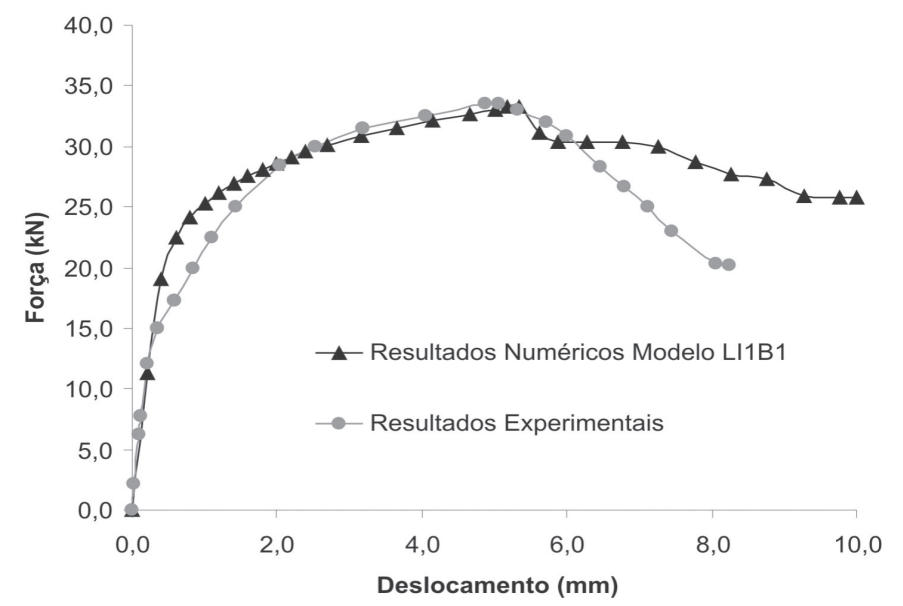

Figura 10. Diagrama Força x Deslocamentos: resultados experimentais e do modelo LI1B1.

No trecho inicial da curva, para valores de deslocamentos menores que $2 \mathrm{~mm}$, o modelo numérico LI1B1, apresentou rigidez ao deslocamento pouco superior àquela rigidez ao deslocamento observada no ensaio experimental. No trecho intermediário da curva, para deslocamentos entre $2 \mathrm{~mm}$ e $5 \mathrm{~mm}$, observouse uma concordância satisfatória entre o resultado numérico do modelo LI1B1 e o resultado experimental. No trecho final da curva, correspondente a deslocamentos maiores que $5 \mathrm{~mm}$, os resultados numéricos divergiram dos resultados experimentais, uma vez que, para deslocamento desta ordem de grandeza já havia ocorrido a ruptura da ligação no ensaio experimental, enquanto no modelo numérico, mesmo para grandes deslocamentos, o modelo ainda continua respondendo com deslocamentos sempre crescentes. 
Comparando-se a força última obtida para o modelo numérico LI1B1, nota-se que esta força última resultou igual a $33,3 \mathrm{kN}$, enquanto que no ensaio, esta mesma força resultou igual a $33,5 \mathrm{kN}$, cuja diferença é da ordem de $0,6 \%$. A Figura11 apresenta as curvas de isotensões, tomadas com referência às tensões equivalentes de von Mises, para o modelo numérico LI1B1.

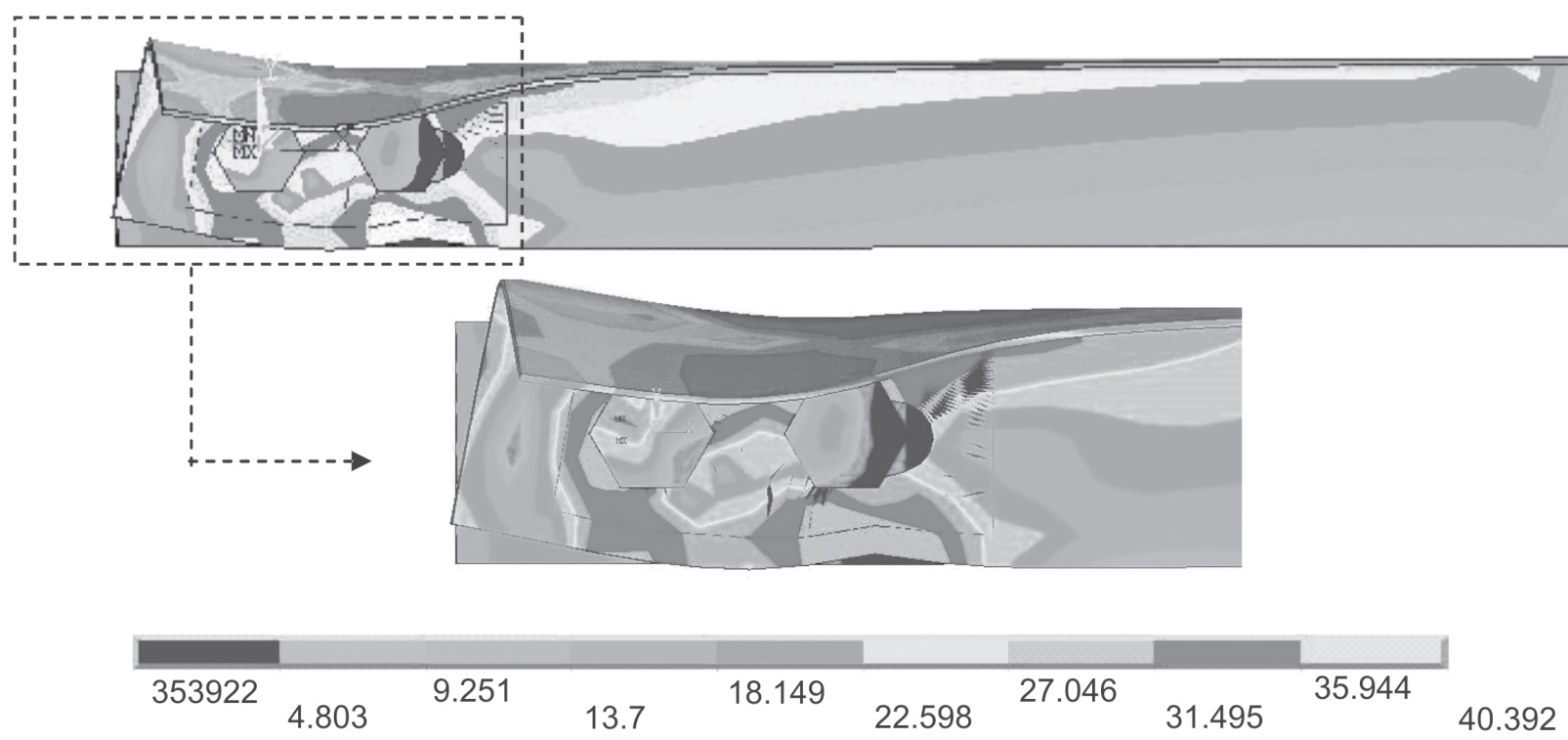

Figura 11. Tensões equivalente de von Mises para o modelo LI1B1. Unidade: $\mathrm{kN} / \mathrm{cm}^{2}$

Na figura 11, pode-se observar que entre o furo e a borda da cantoneira, na seção em que está localizado o primeiro parafuso, aparecem novamente tensões da ordem das tensões de plastificação do aço. Por esta razão, a região em questão pode ser indicada como forte candidata à ocorrência da ruptura do material, como de fato foi possível constatar no ensaio experimental.

A configuração deformada verificada no ensaio experimental foi satisfatoriamente recuperada no modelo numérico LI1B1, conforme representado na Figura 12, em que é ilustrada a ruptura e a configuração deformada da ligação no ensaio experimental, Figura 12a.
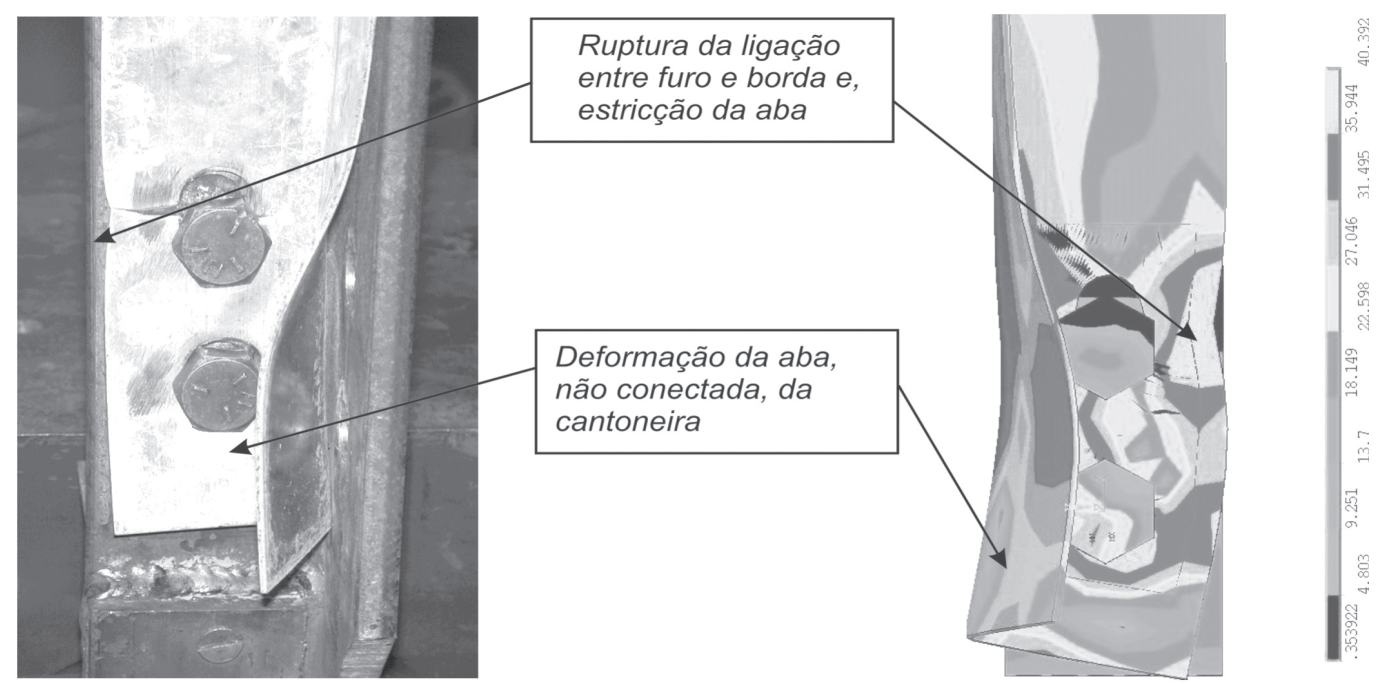

Figura 12. Modelo experimental tipo cantoneira de abas iguais com dois parafusos: (a) Modelo experimental e (b) Modelo numérico LI1C1. 
Na mesma figura, é apresentada ainda uma ampliação da região dos parafusos do modelo numérico LI1B1, Figura 12b, em que se pode observar a deformação ocorrida na aba não conectada da cantoneira, em concordância com o ensaio.

\section{Ligação parafusada em chapa fina com três seções de parafusos}

A Figura 13 apresenta a curva força $\mathrm{x}$ deslocamentos para o modelo $\mathrm{C} 2 \mathrm{C} 1$. No trecho inicial da curva, para valores de deslocamentos menores que $2 \mathrm{~mm}$, o modelo $\mathrm{C} 2 \mathrm{C} 1$ apresentou rigidez ao deslocamento pouco superior àquela obtida no ensaio experimental. No trecho intermediário da curva, para deslocamentos entre 2 mm e $6 \mathrm{~mm}$, observou-se concordância satisfatória entre os resultados numéricos do modelo $\mathrm{C} 2 \mathrm{C} 1$, com o resultado experimental. Pelas mesmas razões já comentadas nos modelos de ligações parafusadas em cantoneiras com dois e três parafusos, no trecho final da curva, os resultados do modelo $\mathrm{C} 2 \mathrm{C} 1$, para deslocamentos maiores que $6 \mathrm{~mm}$, divergiram do resultado experimental..

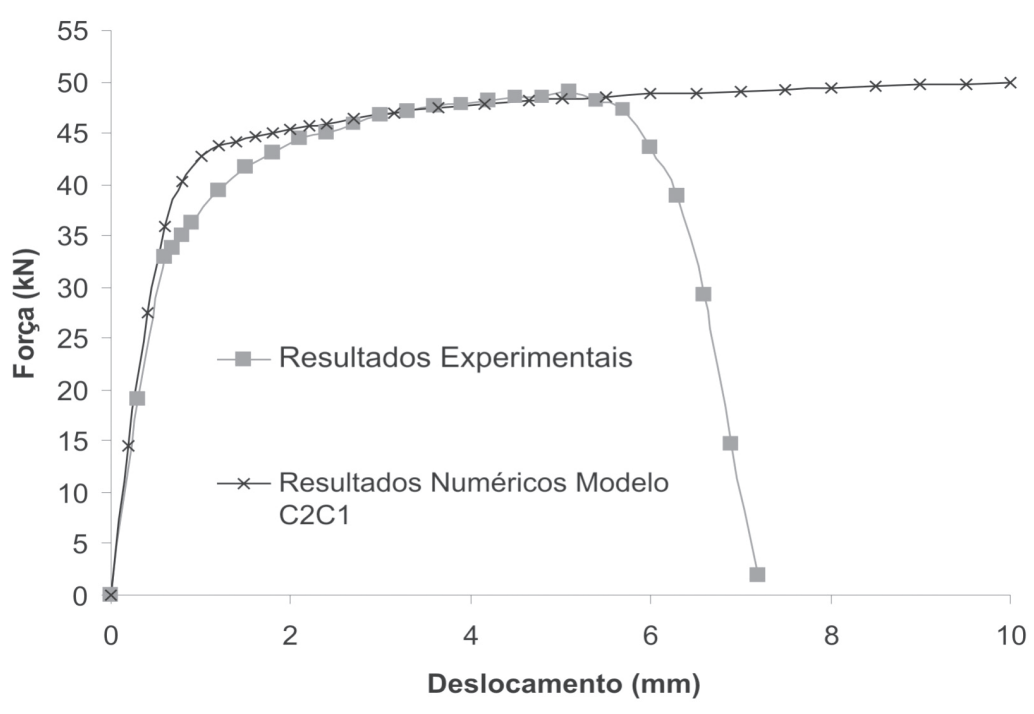

Figura 13. Diagrama Força x Deslocamentos: resultados experimentais e do modelo $\mathrm{C} 2 \mathrm{C} 1$.

Comparando-se a força última obtida para o modelo numérico $\mathrm{C} 2 \mathrm{C} 1$, nota-se que esta resultou igual 49,91 kN, enquanto no ensaio experimental, a mesma força resultou igual a $49,01 \mathrm{kN}$, proporcionando uma diferença de $2 \%$.

A Figura 14 apresenta as curvas de isotensões, tomadas com referência às tensões equivalentes de von Mises, para o modelo numérico C2C1. Nesta figura, pode-se observar que entre os furos aparecem tensões da ordem das tensões de plastificação do aço. Por esta razão, a região em questão pode ser escolhida como forte candidata para a ocorrência da ruptura do material, como de fato foi possível verificar no ensaio experimental.
A configuração deformada verificada no ensaio experimental foi satisfatoriamente recuperada no modelo numérico $\mathbf{C 2 C 1}$, conforme representado na Figura15, em que é ilustrada a ruptura e a configuração deformada da ligação no ensaio experimental, Figura 15b e Figura 15c. Na mesma figura, é mostrada ainda uma ampliação da região dos parafusos do modelo numérico C2C1, Fig. 15a, em que se pode observar a estricção da borda da chapa na região do parafuso, em concordância com o ensaio. 

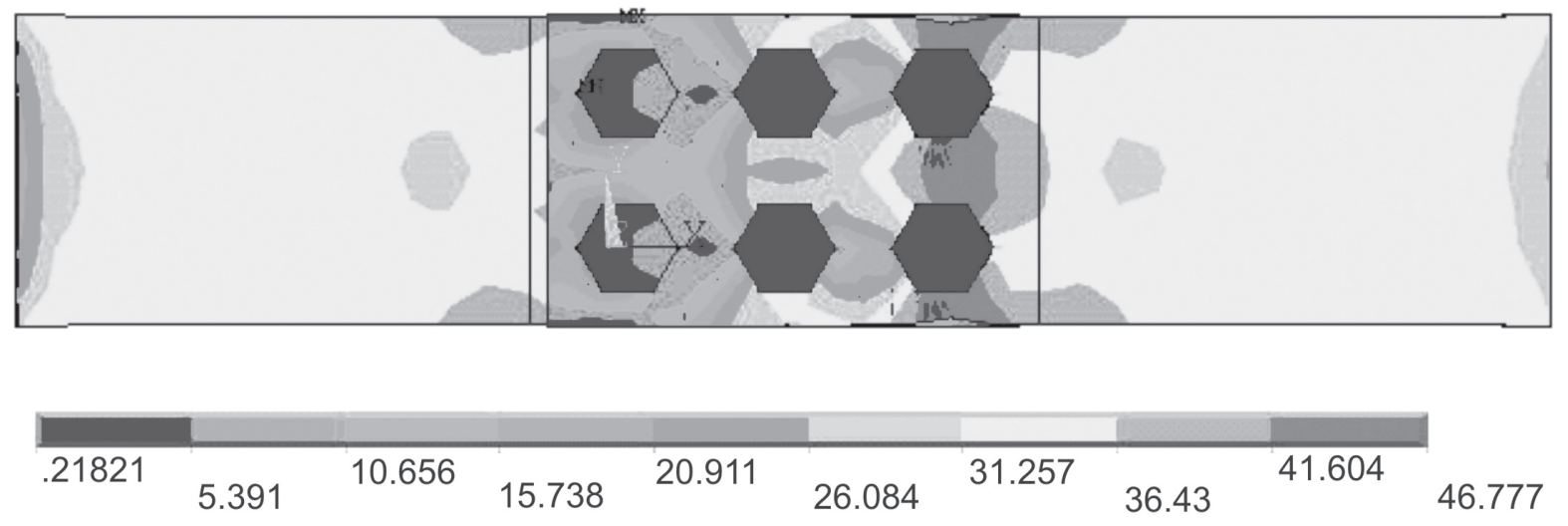

Figura 14. Curvas de isotensões (equivalente de von Mises) para o modelo C2C1. Unidade: $\mathrm{kN} / \mathrm{cm}^{2}$

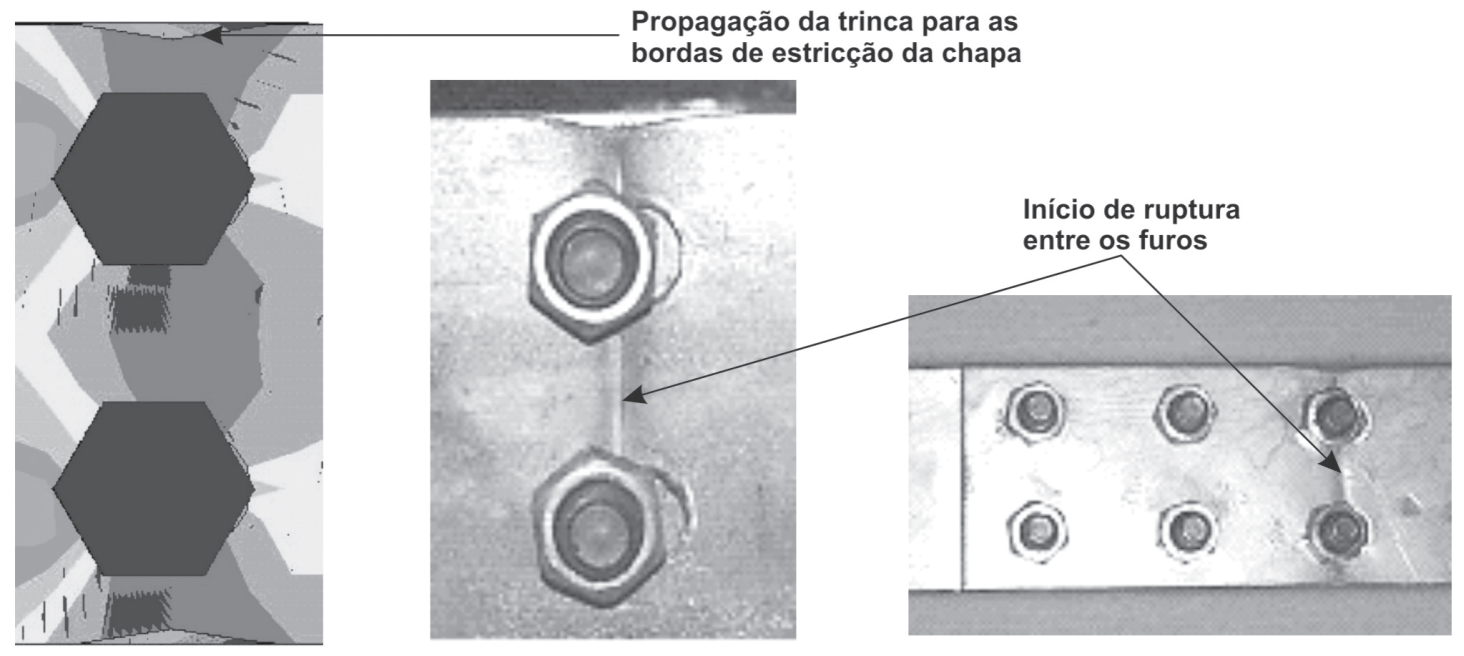

Figura 15. Detalhes: $(\boldsymbol{a})$ Modelo numérico e $(\boldsymbol{b} \boldsymbol{e} \boldsymbol{c})$ ruptura da ligação para o modelo C2C1.

\section{Conclusões}

O presente trabalho objetivou analisar numericamente o comportamento estrutural de ligações parafusadas, em chapas finas e em perfis formados a frio, submetidas à tração axial. Para tanto, foram construídos modelos numéricos com vistas a representar, com o maior rigor possível, os elementos das ligações estudadas, a fim de se estabelecer um padrão de modelagem numérica cujos resultados resultassem confiáveis e satisfatórios.
Para tanto, optou-se por uma análise tridimensional para os modelos de ligações parafusadas em chapas finas e em perfis formados a frio em razão de possíveis dificuldades em estabelecer condições de contorno em campo bidimensional e, consequentemente, uma representação pouco satisfatória dos vínculos reais dessas ligações. A estratégia de modelagem numérica adotada mostrou-se eficiente, quando os resultados obtidos por meio dos modelos numéricos foram comparados àqueles resultados obtidos experimentalmente. 
Observou-se que, para todos os modelos numéricos, as forças últimas obtidas recuperam satisfatoriamente aquelas identificadas nos ensaios experimentais. Vale salientar ainda que a configuração deformada e os modos de falha obtidos nos modelos numéricos resultaram praticamente idênticos àqueles observados nos ensaios experimentais.

Observou-se, ainda, que para grandes deslocamentos, próximos daqueles deslocamentos que provocaram a ruptura das ligações nos ensaios experimentais, os resultados numéricos divergiram dos resultados experimentais. Com efeito, no modelo numérico, mesmo para grandes deslocamentos, o modelo continua respondendo com deslocamentos sempre crescentes, em conseqüência da relação constitutiva adotada para o material.

Tendo em vista os resultados apresentados, pode-se concluir que é possível construir modelos numéricos simples para recuperar o comportamento de ligações parafusadas em perfis formados a frio, e que representem satisfatoriamente os ensaios experimentais, aspecto esse que permite facilitar o estudo destas ligações. Fica ainda como sugestão para estudos futuros, a construção de modelos numéricos mais sofisticados que possam prever a acomodação dos parafusos e eventuais deformações permanentes na região da ligação.

\section{Agradecimentos}

Os autores do presente trabalho agradecem ao $\mathrm{CNPq}$-Conselho Nacional de Desenvolvimento Científico e Tecnológico, pelo apoio concedido ao desenvolvimento da pesquisa em questão.

\section{Referências}

ANSYS. Structural nonlinearities: user's guide for revision 6.0. Local: Editora, 1995.

ASSOCIAÇÃO BRASILEIRA DE NORMAS TÉCNICAS. NB-143. Cálculo de estruturas de aço, constituídas por perfis leves. Rio de Janeiro, 1967.
ASSOCIAÇÃO BRASILEIRA DE NORMAS TÉCNICAS. NBR 14762. Dimensionamento de estruturas de aço constituídas por perfis formados a frio. Rio de Janeiro, 2001.

CHUNG, K. F.; IP, K. H. Finite element modeling of bolted connections between cold-formed stee strips and hot rolled steel plates under static shear loading. Engineering Structures, Guildford, v.22, n. 10, p.1271-1284, oct. 2000.

KRISHNAMURTHY, N.; GRADDY, E. D. Correlation Between 2- And 3 Dimensional Finite Element Analysis Of Steel Bolted End-Plate Connections. Computers and Structures, Elmsford, v.6, p.381-389, 1976.

MAIOLA, C. H. Ligações parafusadas em chapas finas e perfis de aço formados a frio. 2004. Tese (Doutorado)-Escola de Engenharia de São Carlos, Universidade de São Paulo, São Carlos.

MALITE, M. Análise do comportamento estrutural de vigas mistas aço-concreto constituídas por perfis de chapa dobrada. 1993. Tese (Doutorado) Escola de Engenharia de São Carlos, Universidade de São Paulo, São Carlos. 2v.

-Sobre o cálculo de vigas mistas aço-concreto: ênfase em edifícios. 1990. Dissertação (Mestrado) - Escola de Engenharia de São Carlos, Universidade de São Paulo, São Carlos.

REZENDE, P.G. Análise da resposta numérica de ligações parafusadas em chapas finas e perfis formados a frio. São Carlos, 2005. Dissertação (Mestrado) - Escola de Engenharia de São Carlos, Universidade de São Paulo.

YU, W.W. Cold-formed steel design. New York, John Wiley \& Sons, 2000. 